\title{
Performa Mesin Bensin Berbahan Bakar Ethanol 50 dengan Pengaturan Kompresi Rasio dan Durasi Injeksi
}

\author{
Bambang Junipitoyo \\ Moch. Rifai
}

\author{
Politeknik Penerbangan Surabaya \\ Program Studi Teknik Pesawat Udara \\ Kampus Politeknik Penerbangan Surabaya, Jl. Jemur Andayani I/ 73, Surabaya 60236. \\ Email: 1ararya.pendopo@gmail.com,
}

\begin{abstract}
ABSTRAK
Ethanol merupakan bahan bakaryang menghasilkan polutan yang rendah, bahan bakar yang aman, titik nyala etanol tiga kali lebih tinggi dibandingkan bensin dan emisi hidokarbon lebih sedikit. Ethanol 50 merupakan campuran premium 50\% - Bioethanol 50\% yang mempunyai nilai kalor lebih rendah dari premium. Pengaruh rasio kompresi pada kinerja mesin Bensin dengan 50\% bioethanol gasoline bahan bakar dicampur diselidiki pada dinamometer rem air. Sifat bioetanol diukur berdasarkan pada American Society for Testing Material (ASTM) standar. Tujuan penelitian ini adalah mengetahui unjuk kerja mesin bensin yang menggunakan bahan bakar Ethanol E50 dengan pengaturan kompresi rasio dan durasi injeksi. Penelitian dilakukan pada Mesin Bensin 2 silinder 650 cc pada variable speed 2000 5000 rpm, metode yang digunakan adalah dengan mengatur kompresi rasio dan durasi injeksi. Kompresi rasio yang digunakan pada penelitian ini sebesar 9, 10 dan 11. Sedangkan durasi injeksi dilakukan pada digunakan pada penelitian ini sebesar $6 \mathrm{~ms}, 6,6 \mathrm{~ms}$ dan 7,2 ms. Hasil penelitian ini menunjukkan bahwa melalui pengaturan kompresi rasio dan durasi injeksi pada mesin bensin berbahan bakar Ethanol 50, pada kompresi rasio 11 diperoleh kenaikan torsi, daya mengalami kenaikan sebesar 9\%, 4,08\% terhadap E50 standar. dibandingkan dengan menggunakan bensin murni pada kompresi rasio 9,6. Sedangkan pengaruh rasio kompresi dan durasi injeksi dengan pada E50 dapat menaikan konsumsi bsfc 2,1\% dari E50 Standar dan meningkatkan thermal efisiensi dengan 9,2\%.
\end{abstract}

Kata-Kata Kunci: Kompresi rasio , durasi injeksi, ethanol, Mesin Bensin.

\section{Pendahuluan}

Populasi jumlah kendaraan bermotor di Indonesia telah mengalami peningkatan yang cukup tinggi. Salah satu energi alternatif yang saat ini berkembang adalah penggunaan Ethanol. Ethanol adalah bahan bakar yang ramah lingkungan dan merupakan salah satu bentuk energi terbaharui yang dapat diproduksi dari tumbuhan. Bioetanol adalah bahan bakar berkelanjutan yang dapat dihasilkan dari Suger tebu atau energi terbarukan lainnya sumber sehingga digunakan paling banyak. Selain itu, bioetanol terdiri dari sekelompok senyawa kimia yang molekul mengandung gugus hidroksil $(\mathrm{OH})$ yang terikat pada atom karbon. Kandungan oksigen bahan bakar bioethanol nikmat pembakaran lanjut bensin [2]. Juga, bioetanol digunakan untuk meningkatkan angka oktan bensin. Dapat disimpulkan bahwa menggunakan bioetanol-bensin bahan bakar dicampur dapat mengurangi polusi udara dan penipisan yang bahan bakar bensin secara bersamaan. Banyak peneliti yang mempelajari pengaruh bahan bakar bioetanol pada kinerja dan emisi polutan dari mesin dengan eksperimental.

Sudarmanta. B, et. al, (2014), melakukan penelitian Influence of bioethanol-gasoline blended fuel on performance and emissions characteristics from port injection Sinjai Engine $650 c c$, pada penambahan bioethanol $15 \%$ diperoleh peningkatan daya sebesar 10,29\% dibanding bensin. Sedangkan pada prosentase bioethanol yang lebih besar (E20) cenderung menurunkan 
daya 8,96\% dibanding bensin. Yousufuddin syed (2007); melakukan penelitian dengan ethanolbensin tanpa timbal (E0, E10, E25, E35, E65), Variable rasio kompressi (9:1 dan 11:1), Rasio udara-bahan bakar. Pikunas. A (2003) melakukan penyelidikan tentang campuran bahan bakar $10 \%$ ethanol-bensin.

Pada mesin pembakaran internal, peningkatan tekanan efektif rata-rata dengan meningkatnya rasio kompresi adalah konsekuensi dari peningkatan puncak tekanan silinder. Tekanan meningkat diikuti oleh pembakaran kenaikan suhu, membutuhkan terbelakang pengapian untuk menghindari ledakan. Rasio kompresi tinggi memungkinkan untuk meningkatkan efisiensi konversi bahan bakar, sebagai efisiensi mesin termal meningkat. Dengan peningkatan kompresi rasio dapat menghasilkan pembakaran yang optimal yang berpengaruh pada peningkatan unjuk kerja. Nilai kalor bioethanol yang rendah memungkinkan mengatur durasi injeksi untuk memperoleh konsumsi bahan bakar E50 lebih banyak sehingga akan diperoleh daya yang lebih besar. Dengan peningkatan durasi injeksi dapat menghasilkan pembakaran yang optimal yang berpengaruh pada peningkatan unjuk kerja mesin seperti : torsi, daya dan emisi. Dari latar belakang tersebut diatas yang melatarbelakangi penulis untuk melakukan penelitian tentang Ethanol dengan pengaturan kompresi rasio dan durasi injeksi.

\section{METODE}

Pengujian dilakukan pada Mesin Bensin 2 silinder 4 langkah dengan kapasitas engine $650 \mathrm{cc}$ single fuel gasoline engine dengan menggunakan bahan bakar Ethanol 50. Untuk mendapatkan kinerja engine yang baik, khususnya daya, dilakukan pengaturan kompresi rasio dan durasi injeksi dengan diuji menggunakan waterbrake chasis dynamometer dan Sinjai Interface Sistem. Proses modifikasi mesin dan seluruh rangkaian pengujian dilakukan di Laboratorium Motor Bakar. Penelitian yang dilakukan yaitu :

Adapun skema penelitian adalah sebagai berikut:

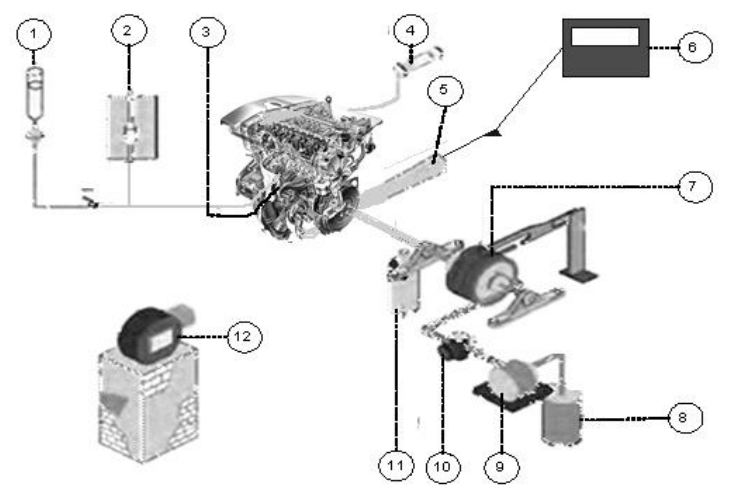

Gambar 1 Skema pengujian

Dalam melakukan pengujian eksperimen maka dimulai dengan melakukan urutan sebagai berikut:

1) pengujian engine dengan menggunakan bahan bakar premium.

2) pengujian engine dengan menggunakan bahan bakar Ethanol E50 dengan melakukan setting kompresi rasiodan durasi injeksi. 


\section{HASIL DAN PEMBAHASAN}

Setelah melakukankan penelitian, maka data yang diperoleh perlu dideskripsikan terlebih dahulu kemudian dianalisis hasilnya dan digrafikkan, tujuannya adalah untuk menjelaskan data yang diperoleh agar tidak terjadi perbedaaan dalam mempersepsikan data. Berikut analisa data pada pengujian eksperimen ini adalah sebagimana berikut:

1. Analisa Torsi Mesin tiap pengaturan kompresi rasio dan durasi injeksi.

Pada gambar 2. Menunjukkan pengaruh pengaturan rasio kompresi rasio dan durasi injeksi pada torsi keluaran. dimana saat engine menggunakan bahan bakar premium nilai torsi sebesar 47,15 Nm sedangkan ketika menggunakan bahan bakar E50 standar sebesar 40,71 $\mathrm{Nm}$ atau mengalami penurunan nilai torsi rata-rata sebesar $14,9 \%$. Berdasarkan pada fenomena tersebut maka pada penelitian ini dilakukan upaya untuk memodifikasi dengan cara melakukan pengaturan kompresi rasio pada bahan bakar E50 agar didapatkan nilai torsi yang lebih optimum.

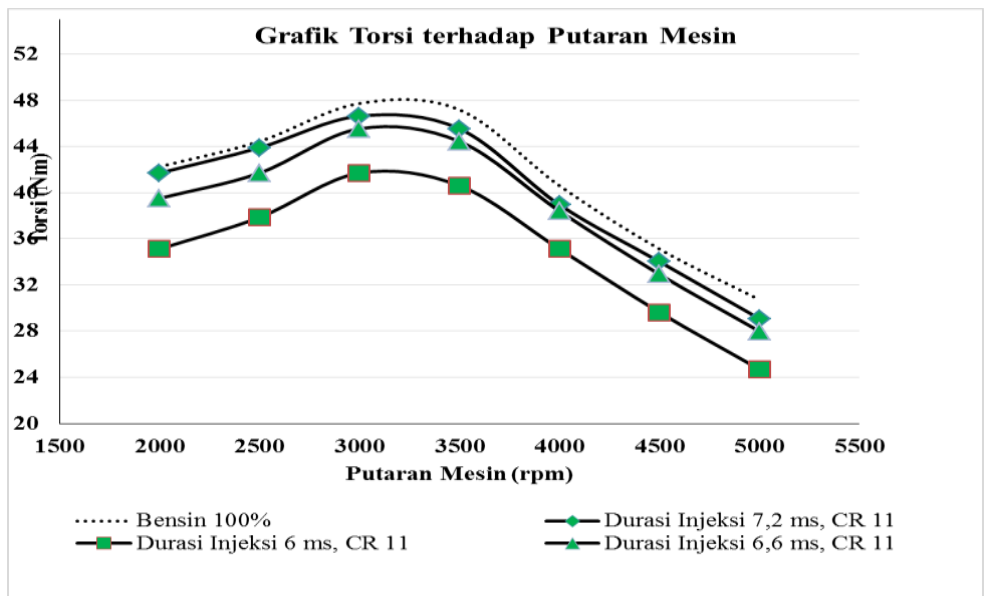

Gambar 2. Grafik Torsi terhadap Putaran Mesin

2. Analisa Daya Mesin tiap pengaturan kompresi rasiodan durasi injeksi

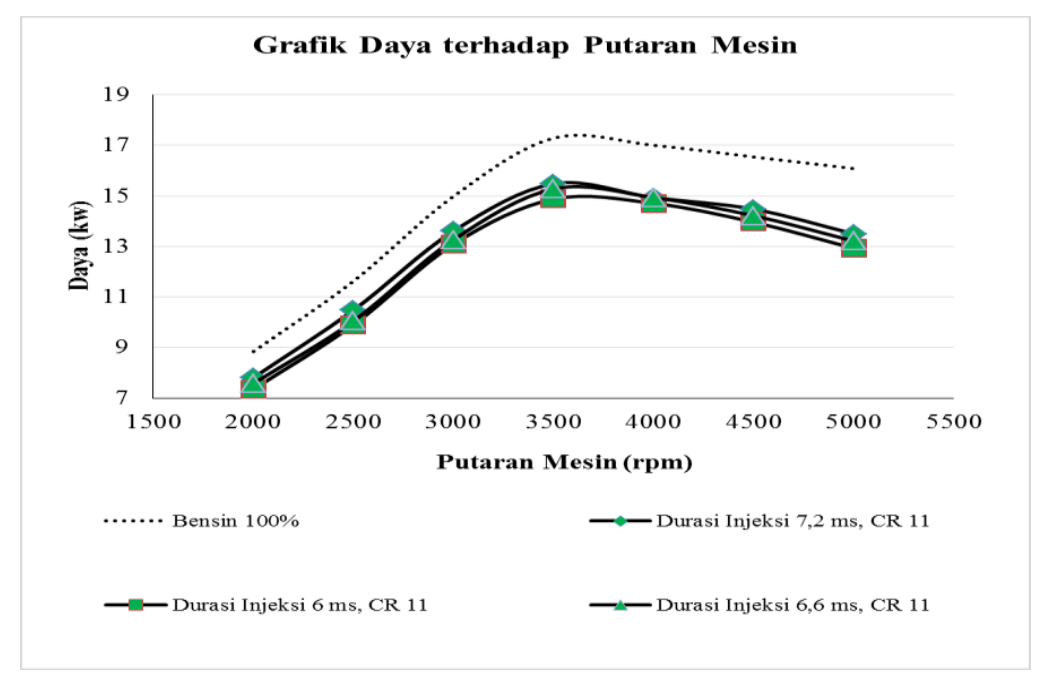

Gambar 3. Grafik Daya terhadap Putaran Mesin 
Gambar 3 menunjukkan bahwa daya mengalami kenaikan seiring naiknya putaran mesin untuk mencapai daya maksimum dan selanjutnya turun pada putaran tinggi. Daya tertinggi 15,8 kWatt terjadi pada putaran $3500 \mathrm{rpm}$ yang diperoleh pada pengaturan kompresi rasio 11 atau terjadi kenaikan 4,08\% dibanding E50 standar.

3. Analisa Spesific Fuel Consumption (Sfc) Mesin tiap pengaturan kompresi rasio dan durasi injeksi.

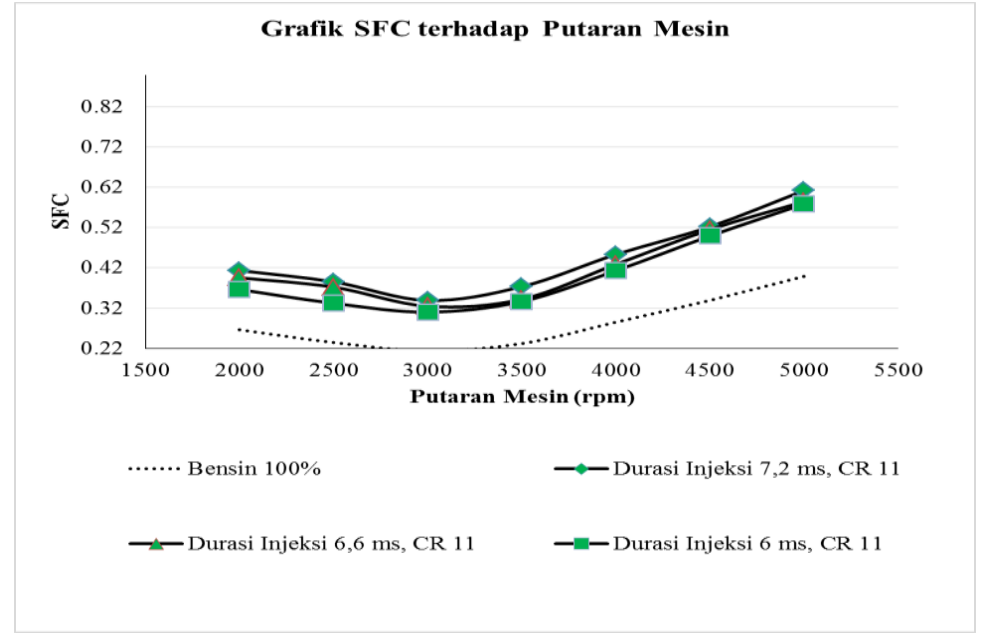

Gambar 4. Grafik Sfc terhadap Putaran Mesin

Pada gambar 4. menunjukan pengaruh kompresi rasio dan durasi injeksi terhadap konsumsi bahan bakar (Sfc). Penambahan kompresi rasio dan durasi injeksi berpengaruh terhadap konsumsi bahan bakar. Konsumsi bahan bakar turun pada kondisi bertambahnya putaran mesin untuk mencapai sfc minimum selanjutnya mengalami kenaikan seiring bertambahnya putaran mesin. Sfc minimum $0,32 \mathrm{~kg} / \mathrm{kW}$.jam terjadi pada putaran $3500 \mathrm{rpm}$ dengan kompresi rasio 11 mengalami kenaikan 2,1\% dibandingkan dengan E50 standar.

4. Analisa Effisiensi Thermal Mesin tiap pengaturan kompresi rasio dan durasi injeksi.

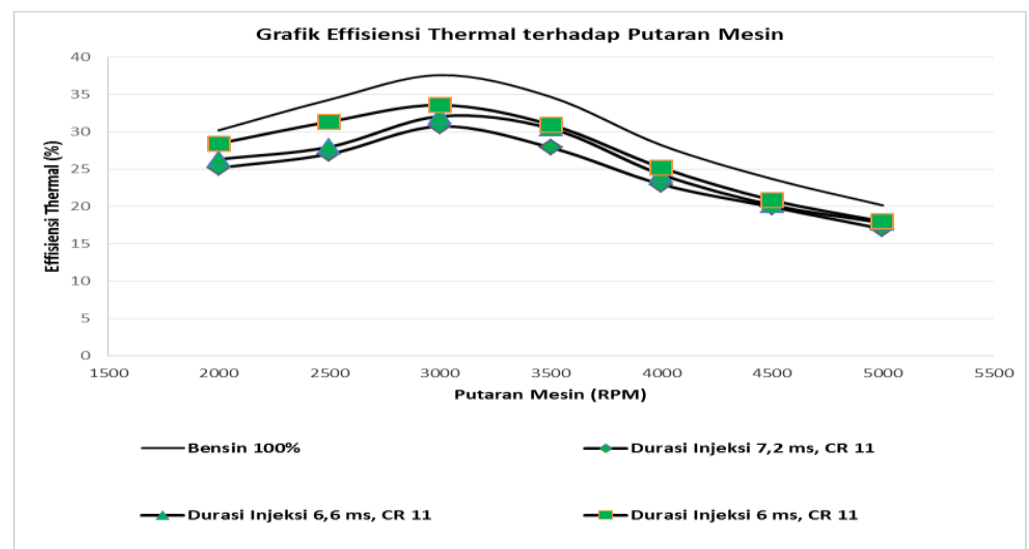

Gambar 5. Grafik Effisiensi Thermal terhadap Putaran Mesin 
Pada gambar 5. Menunjukkan grafik hubungan Effisiensi thermal terhadap putaran mesin. titik optimum dari efisiensi thermal pada pemakaian bahan bakar premium sebesar 34,5\%, dan untuk E50 standar sebesar 31,6 \% keduanya terjadi pada putaran engine $3000 \mathrm{rpm}$. Dengan penambahan kompresi rasio dan durasi injeksi diperoleh kenaikan efisiensi thermal optimal pada rasio kompresi 11 sebesar 9,2\%.

\section{KESIMPULAN}

\section{Kesimpulan}

Berdasarkan hasil analisis data dan pembahasan, dapat disimpulkan bahwa:

1. Dengan melakukan setting kompresi rasio dan durasi injeksi yang tepat maka akan didapatkan nilai optimasi pada kenaikan torsi, daya, sfc dan efisiensi yang terbaik.

2. Dengan melakukan pengaturan kompresi rasio dan durasi injeksi pada mesin bensin berbahan bakar E50 didapatkan performa yang lebih optimal dibandingkan saat menggunakan settingan E50 standar.

\section{Saran}

1. Perlu dilakukan penelitian lebih lanjut supaya mendapatkan settingan kompresi dan waktu pengapiandan durasi injeksi yang optimal pada setiap putaran engine.

\section{DAFTAR PUSTAKA}

"Fuel Quality Monitoring “. Langit Biru, Kementerian Lingkungan Hidup, (2007), pp $(16,17,25)$

N. Jeuland, N, Montagne \& X. Gautrot. (2004), "Potentiality of Ethanol as a Fuel for Dedicated Engine”. Oil \& Gas Science and Technology - Rev. IFP, , Institut Frances du Petrole, Vol. 59 No.6, pp. 559-570

Li - Wei Jia , Mei - Qing Shen, Juni Wang dan Man - Qun Lin 2005. Pengaruh etanol bensin dicampur bahan bakar karakteristik emisi dari empat -stroke mesin sepeda motor . Jurnal Bahan Berbahaya A123 : 29-34

Heywood, (1988), Internal Combustion Engine Fundamental, New York, Mc Graw Hill.

Ganesan.V, (2003), Internal Combustion Engine., NewDelhi, McGraw Hill.

Pulkrabek. W, (2002), Engineering fundamental of the internal combustion engine, , New Jersey, Prentice Hall.

Sudarmanta B, (2014), "Influence of a bioethanol-gasoline blended fuel on performance and emissions characteristic from port Injection Sinjai Engine 650 cc”. Applied Mechanics and Materials Vol. 493. pp 273-280.

Mardani. R, (2007), "Karakteristik pembakaran dari variasi campuran ethanol-gasoline (E30E50) terhadap unjuk kerja sepeda motor 4 stroke fuel injection 125cc". Tugas Akhir Teknik Mesin, Universitas Indonesia, pp. 34-50. 